\title{
THE EFFECT OF SODIUM ION ON THE INITIAL PHASE OF THE SINOATRIAL PACEMAKER ACTION POTENTIALS IN RABBITS
}

\author{
Akinori Noma and Hiroshi IRISAWA \\ Department of Physiology, School of Medicine, Hiroshima University, \\ Kasumicho, Hiroshima 734, Japan
}

\begin{abstract}
Summary The maximum rate of rise of depolarization of the isolated rabbit S-A node cells was studied with an intracellular microelectrode. Both the amplitude and the maximum rate of rise of depolarization reduced in proportion to the extracellular sodium concentration, but the reduction in the maximum rate of rise of depolarization was greater than that in the amplitude of action potentials.

The frequency of spontaneous activities and the duration of action potentials were increased during application of depolarizing current, while they were both reduced during application of hyperpolarizing current. Both the amplitude of the action potential and the maximum rate of rise of depolarization showed voltage dependent characteristics. The maximum value of the maximum rate of rise of depolarization in pacemaking cells ranged from 2 to $11 \mathrm{~V} / \mathrm{sec}$ and was quantitatively lower than other myocardial fibers. The maximum value of the maximum rate of rise of depolarization in $50 \% \mathrm{Na}^{+}$solution was reduced to approximately $1 / 2$ of the control in normal $\mathrm{Na}^{+}$solution.

A sigmoidal relationship was observed between the membrane potential and the maximum rate of rise of depolarization. When the temperature of the perfusate was lowered, the sigmoidal curve shifted toward the negative direction. It is concluded that sodium ion is responsible for the generation of the initial phase of the S-A node action potentials, as in other myocardial cells. However, the amount of ionic current required for spike generation is quantitatively smaller than other myocardial cells.
\end{abstract}

It is well established in the myocardium that the rapid inflow of sodium ion causes the initial rising phase of the action potential. Recent electrophysiological findings on the atrial and ventricular fibers have demonstrated that the maximum rate of rise of depolarization is dependent on the extracellular sodium ion con-

Received for publication July 8, 1974

野間昭典, 入沢 宏 
centration $\left(\left[\mathrm{Na}^{+}\right]_{\mathrm{o}}\right)$, while the amplitude of the action potential is largely dependent on the extracellular sodium and calcium ion concentration (NIEDERGERKE and OrKand, 1966; Seyama, 1969; BeEler and Reuter, 1970b). In the sinoatrial node (S-A node) cells, the maximum rate of rise of depolarization is very low compared with other myocardial fibers. The spontaneous discharge rate of the S-A node cells is not highly dependent on $\left[\mathrm{Na}^{+}\right]_{0}$ as in the case of the Purkinje fiber (WEST, 1961). Also, it is well known that the action potential of the S-A node cell is not sensitive to tetrodotoxin (LENFANT et al., 1968; YAMAGISHI and SANO, 1966; IrISAWA, 1972). These phenomena suggest that the S-A node cell is relatively insensitive to changes of $\left[\mathrm{Na}^{+}\right]_{0}$. However, no quantitative measurement of the maximum rate of rise of depolarization in response to $\mathrm{Na}^{+}$reduction in S-A node cells is available. The maximum rate of rise of depolarization gives one of the essential clues on the initial phase of the action potential, particularly in those myocardial cells in which the voltage clamp method is not readily applicable (WEIDMANN, 1955).

The authors studied the effect of depletion of $\left[\mathrm{Na}^{+}\right]_{0}$ on the relationship between the maximum rate of rise of depolarization and the membrane potential in the isolated pacemaker cells from the rabbit S-A node. A sigmoidal relationship between the maximum rate of rise of depolarization and the membrane potential was demonstrated. It was also found that the maximum rate of rise of depolarization in the S-A node cell is dependent upon $\left[\mathrm{Na}^{+}\right]_{0}$.

\section{METHODS}

Materials. Rabbits weighing $1-2 \mathrm{~kg}$ were anesthetized by intravenous injection of $40 \mathrm{mg} / \mathrm{kg}$ of sodium pentobarbital (Nembutal). The heart was removed from the body and dissected in aerated Tyrode solution. The right atrium was isolated from the remaining tissue and opened by a longitudinal cut in its free wall to expose the endocardial surface of the S-A node. The S-A node region was located within the area surrounded by the sinoatrial ring bundle (PAES DE CARvalho et al., 1959), and it was identified by recording the transmembrane potentials. The S-A node tissue (3-4 $\mathrm{mm}$ in diameter) was further dissected into small pieces $(1 \times 1 \mathrm{~mm})$, and these were used for the recording. Temperature of the bath was maintained at $35-36^{\circ} \mathrm{C}$.

Solutions. A modified Tyrode solution containing $\mathrm{NaCl} 136.9, \mathrm{KCl} 2.7$, $\mathrm{CaCl}_{2} 1.8, \mathrm{MgCl}_{2}$ 0.5, $\mathrm{NaHPO}_{4} 1.5$, and $\mathrm{Na}_{2} \mathrm{HPO}_{4} 4.5$ in mM with pH of 7.4 was used instead of a standard $\mathrm{HCO}_{3}{ }^{-}$-containing Tyrode solution in the present experiment. The $\mathrm{Na}^{+}$-free solution contained Tris- $\mathrm{HCl}$ 108.7, Tris base 41.1, $\mathrm{KCl}$ 2.7, $\mathrm{CaCl}_{2}$ 1.8, and $\mathrm{MgCl}_{2} 0.5$ in $\mathrm{mm}$ and its $\mathrm{pH}$ was 7.4. Various concentrations of $\mathrm{Na}^{+}$deficient solution were prepared by mixing normal Tyrode solution with $\mathrm{Na}^{+}$-free Tyrode solution.

Electrophysiological measurements. The electrodes were suspended from 
an $\mathrm{Ag}-\mathrm{AgCl}$ wire connected mechanically to $25 \mu \mathrm{m}$ tungsten wire. This modification of the method originally developed by WOODBURY and BRADY (1956) eliminated polarization and reduced the drift significantly. Electrodes were filled with $3 \mathrm{M} \mathrm{KCl}$; their resistance was approximately 40 megohms. A conventional high input impedance microelectrode amplifier was employed to record the membrane potential from the pacemaker tissue. A differentiator circuit with a time constant of $5 \mathrm{msec}$ coupled in parallel with a DC amplifier was used to measure the maximum rate of rise of depolarization. Action potentials, the maximum rate of rise of depolarization and the applied current were displayed on a cathode ray oscilloscope (VC-7 Nihon Kohden) and recorded photographically.

Because of the variety of fibers in S-A node cells and the presence of a shift phenomenon among the pacemaker cells, it was preferable to record the membrane potential in the cell in which the microelectrode remained fixed for at least 10 min. The data were collected from these cells in this experiment.

A strip chart recorder was employed for recording the long term potential changes. To change the membrane potential, current was made to flow using the single sucrose gap method shown in Fig. 1. The principle of the single sucrose gap method used in the present study is practically the same as that used elsewhere (Giebisch and Weidmann, 1971; Morad and Trautwein, 1968). The

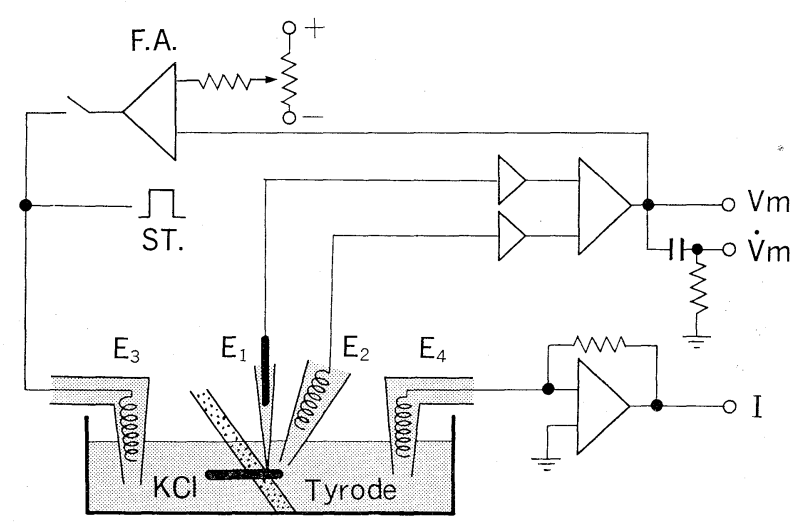

Fig. 1. Schematic diagram of an S-A node cell preparation in three compartments and the electronic circuit. Sucrose solution was perfused through the central gap as shown in dots. E1: reference microelectrode. Thick Ag-AgCl wire was connected mechanically to $25 \mu \mathrm{m}$ tungsten wire. The silver wire was inserted into the tapered part of the microelectrode. $\mathrm{E} 2$ : indifferent agar- $\mathrm{AgCl}$ electrode. $\mathrm{E} 3$ and $\mathrm{E} 4$ : agar- $\mathrm{AgCl}$ electrode for polarization of the S-A node cells. St: stimulator including the stimulus isolation unit. Vm: output from the operational amplifier to record the membrane potential. $\dot{V}$ : output of the differentiating circuit for the continuous monitoring of the maximum rate of rise of depolarization. I: current monitor. F. A: feedback amplifier for the "voltage clamp." 
central sucrose gap chamber was $0.6-0.8 \mathrm{~mm}$ in width and oriented obliquely so as to facilitate the penetration of microelectrodes. To separate the Tyrode compartment from the $\mathrm{KCl}$ compartment, two cellulose membranes $0.3 \mathrm{~mm}$ in thickness were used. A small hole was punctured in the center of each membrane. A strip of muscle was drawn through the holes and fixed into position for electrical recordings. The length of the pacemaker tissue in Tyrode solution ranged from 0.3 to $1.0 \mathrm{~mm}$. The maximum diastolic potential was changed by applying a constant current of various intensities across the sucrose gap. Since the diastolic potential slowly changed during the application of the current, it was preferable to hold the membrane potential at a constant level. In several experiments, the "voltage clamp" method was applied. The feedback amplifier was the same as that described by BEELER and REUTER (1970a). The maximum rate of rise of depolarization of the action potential immediately after the release of the clamp was measured.

\section{RESULTS}

Variations in the maximum rate of rise of depolarization in $S$-A node cells

When the S-A node tissues were dissected into small pieces $(0.5-1.0 \mathrm{~mm}$ in diameter), most of them showed spontaneous activity. Two different types of cells were identified as having a smooth transition of slow diastolic depolarization into the 0 -phase of the action potential or having an abrupt transition. In these dissected specimens, the former cells are defined as pacemaking cells and the latter as follower cells. The pacemaking cells showed a pattern of action potential similar to that of the true pacemaker cells described by WeST (1955), SANO and YAMAGISHI (1965), and LU (1970). The membrane potentials were measured in 100 pacemaking cells and 45 follower cells. The maximum diastolic potentials ranged from 43.0 to $70.0 \mathrm{mV}(57.9 \pm 7.7 \mathrm{mV}$; mean \pm S.D. $)$ in the pacemaking cells, while in the follower cells they ranged from 41.0 to $75.0 \mathrm{mV}(61.5 \pm 4.7 \mathrm{mV})$.

The difference in the maximum diastolic potentials and overshoot of the action potentials between the two types of cells were statistically insignificant. On the other hand, the difference in the mean value of the maximum rate of rise of depolarization was statistically significant $(P<0.05)$ (Table 1$)$. The maximum rate of rise of depolarization ranged from 0.53 to $8.5 \mathrm{~V} / \mathrm{sec}(3.5 \pm 1.6 \mathrm{~V} / \mathrm{sec})$ in the pacemaking cells and from 1.6 to $45.0 \mathrm{~V} / \mathrm{sec}(11.2 \pm 9.3 \mathrm{~V} / \mathrm{sec})$ in the follower cells.

In Fig. 2, the maximum rate of rise of depolarization is plotted against the maximum diastolic potentials. In approximately $80 \%$ of the pacemaking cells, the value of the maximum rate of rise of depolarization was less than $5 \mathrm{~V} / \mathrm{sec}$. On the other hand, in approximately $13 \%$ of the follower cells the value was under $5 \mathrm{~V} / \mathrm{sec}$. Obviously, transitions may exist between these two types of cells. In spite of the large variation in sampling values, there was a general trend for the 
Table 1. Comparison of the pacemaking cell and the follower cell in the $\mathbf{S}-\mathbf{A}$ node region. Number of measurements is shown in parentheses.

\begin{tabular}{ccccc}
\hline & $\begin{array}{c}\text { Max diastolic } \\
\text { potential }(\mathrm{mV})\end{array}$ & $\begin{array}{c}\text { Overshoot } \\
(\mathrm{mV})\end{array}$ & $\begin{array}{c}\text { Amplitude } \\
(\mathrm{mV})\end{array}$ & $\begin{array}{c}\text { Max. rate of } \\
\text { rise }(\mathrm{V} / \mathrm{sec})\end{array}$ \\
\hline $\begin{array}{c}\text { Pacemaking } \\
\text { cell (100) }\end{array}$ & $57.9 \pm 7.7$ & $10.7 \pm 5.5$ & $68.7 \pm 7.6$ & $3.5 \pm 1.6$ \\
Follower cell (45) & $\begin{array}{l}61.5 \pm 4.7 \\
t=0.2\end{array}$ & $\begin{array}{l}12.7 \pm 6.1 \\
t=0.3\end{array}$ & $\begin{array}{l}72.3 \pm 9.2 \\
t=0.3\end{array}$ & $\begin{array}{l}11.2 \pm 9.3 \\
t=2.0\end{array}$ \\
\hline
\end{tabular}

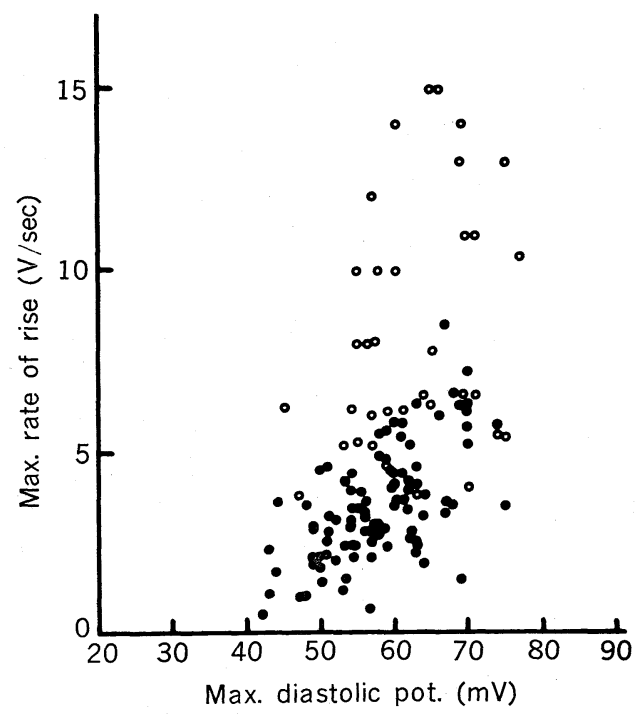

Fig. 2. Distribution of the maximum rate of rise of depolarization and the maximum diastolic potential of S-A node cells. Solid circles indicate the data taken from pacemaking cells, while open circles show those of follower cells.

maximum rate of rise of depolarization to increase as the membrane potential hyperpolarized.

Effect of reduction of $\left[\mathrm{Na}^{+}\right]_{\mathrm{o}}$ on $\mathrm{S}$ - $A$ node action potentials

Spontaneous action potential continued within $\mathrm{Na}^{+}$deficient solution until $\left[\mathrm{Na}^{+}\right]_{\text {o }}$ was reduced to less than $30 \%$ of the normal saline in the pacemaking cells. When $\left[\mathrm{Na}^{+}\right]_{\text {o }}$ was reduced to $30 \%$ of normal, the pacemaking cell shown in Fig. 3 eventually ceased its spontaneous activity. Within one minute after perfusion of $30 \%\left[\mathrm{Na}^{+}\right]_{\mathrm{o}}$, the maximum diastolic potential increased by a few millivolts; thereby, the amplitude and the maximum rate of rise of depolarization of the action potential increased (Fig. 3-2). Thereafter, the maximum diastolic potential gradually reduced, and correspondingly, the amplitude of the action potential and the maximum diastolic potential gradually reduced (Fig. 3-3, 3-4). Finally, after 5 min, oscillatory activity described by WEST (1961) was observed (Fig. 3A5). 


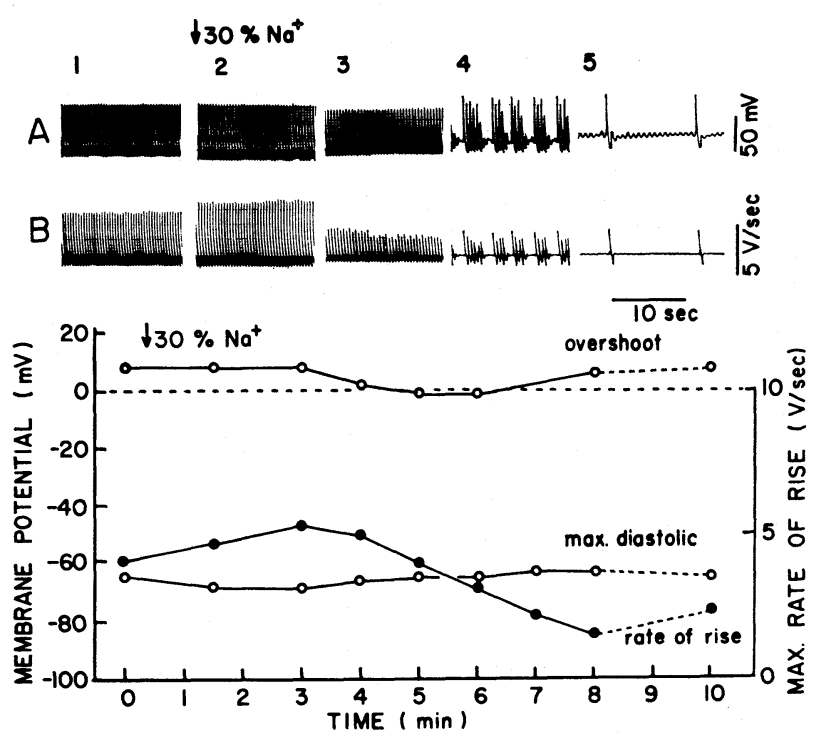

Fig. 3. Effect of reduction of $\left[\mathrm{Na}^{+}\right]_{0}$ on S-A node action potentials. A: action potential. B: rate of rise of depolarization. Lower graph illustrates the variation in the membrane potential (open circle) and the maximum rate of rise of depolarization (solid circle). Measurements at 10 minutes were obtained when the cell was stimulated electrically.

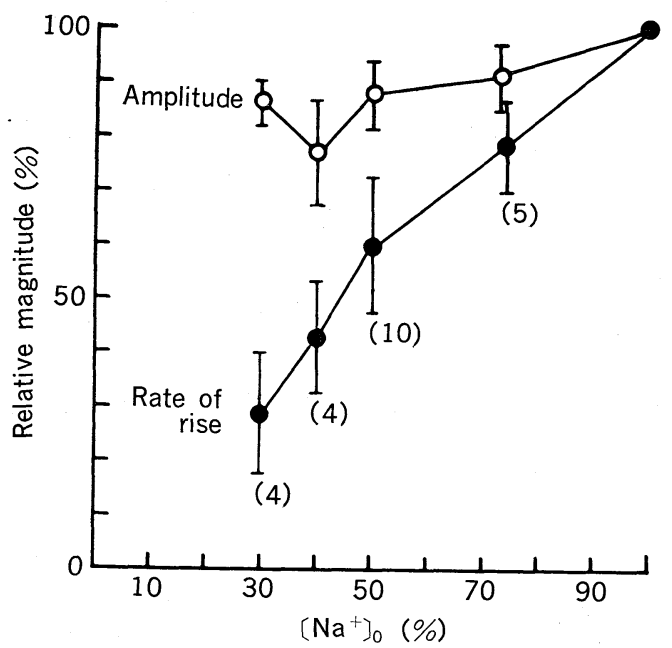

Fig. 4. Effects of $\left[\mathrm{Na}^{+}\right]_{\text {o }}$ on the action potential of the S-A node cells. Abscissa: extracellular $\mathrm{Na}^{+}$concentration, ordinate: relative magnitudes of amplitude (open circle) and the maximum rate of rise of depolarization (solid circle). Numerals in parentheses indicate the number of samples. Individual point gives the average and the vertical bar indicates its S.D. Points are joined by straight lines. 
After the spontaneous activity ceased, the electrical stimulation usually elicited a train of repetitive responses. The initial action potential showed the highest peak followed by a gradual reduction in spike potential. A similar pattern in potentials is shown in Fig. 3A4, although in this instance the potentials were elicited spontaneously. The initial transient hyperpolarization followed by a depolarization of the maximum diastolic potential was observed in 40,50 , and $75 \%\left[\mathrm{Na}^{+}\right]_{\text {o }}$ solution.

These changes in the maximum diastolic potential and the maximum rate of rise of depolarization were also observed in the follower cells. However, in the follower cells, an abrupt cessation of spontaneous activity due to a conduction block was frequently observed in concentrations higher than $30 \%\left[\mathrm{Na}^{+}\right]_{0}$.

The general trend of the response patterns was qualitatively similar in 23 series of experiments, and they are summarized in Fig. 4. Both the amplitude and the maximum rate of rise of depolarization reduced in proportion to $\left[\mathrm{Na}^{+}\right]_{0}$. The decrease in amplitude in response to $\mathrm{Na}^{+}$deficiency was less than $20 \%$ within $30 \%\left[\mathrm{Na}^{+}\right]_{\mathrm{o}}$, but the decrease in the maximum rate of rise of depolarization was approximately $70 \%$.

Effects of $50 \%\left[\mathrm{Na}^{+}\right]_{0}$ on the maximum rate of rise of depolarization at various membrane potentials

In the preceding section, the reduction of $\left[\mathrm{Na}^{+}\right]_{0}$ finally resulted in a slight depolarization of the maximum diastolic potential in S-A node cells. The reduction of the maximum rate of rise of depolarization in $\mathrm{Na}^{+}$deficient solution might be partly due to the inactivation mechanisms. Therefore, the effect of the change of membrane potential on the action potential in S-A node cells was examined (Fig. 5). In A, two instances of current application in normal $\mathrm{Na}^{+}$ Tyrode solution are shown. The application of depolarizing current to this cell caused an increase of spontaneous frequency and reduction of the amplitude and the maximum rate of rise of depolarization (Fig. 5A1). Hyperpolarizing current produced an opposite effect with respect to spontaneous frequency.

At a stronger current intensity, cessation of spontaneous activity was observed. The maximum rate of rise of depolarization, however, was lower during current application, but was higher than the control value in the action potential elicited at the disruption of the current.

After recording the maximum rate of rise at various membrane potentials in normal Tyrode solution, the same cell was perfused with $50 \%\left[\mathrm{Na}^{+}\right]_{\mathrm{o}}$ Tyrode solution. The maximum rate of rise of depolarization was reduced during application of the depolarizing current and was increased immediately after cessation of hyperpolarizing current (Fig. 5B). Eleven examples of the maximum rate of rise of depolarization in normal Tyrode solution and eight examples in $50 \%\left[\mathrm{Na}^{+}\right]_{\circ}$ are plotted against the maximum diastolic potential in Fig. 5C. As demonstrated in this figure, the maximum rate of rise of depolarization is voltage dependent and 

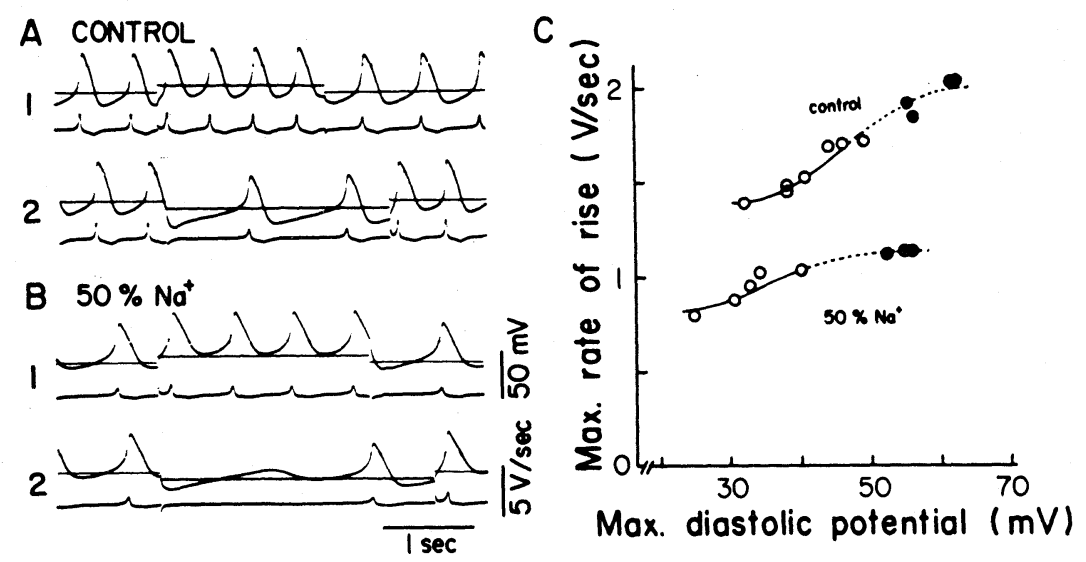

Fig. 5. Effect of constant current on the action potential of the S-A node cells within normal (A) and $\mathrm{Na}^{+}$reduced (B) solution. The top trace indicates the current record, the middle, the action potential and the bottom, the maximum rate of rise of depolarization. 1: application of depolarizing current. 2: application of hyperpolarizing current. $\mathrm{C}$ : relationship between the maximum diastolic potential and the maximum rate of rise of depolarization in normal Tyrode solution and in $50 \%\left[\mathrm{Na}^{+}\right]_{0}$ solution. Solid circles in the graph indicate that the points were obtained immediately after current application.

it is apparently reduced at any membrane potential following reduction of $\left[\mathrm{Na}^{+}\right]_{0}$.

Sigmoidal relationship between the maximum diastolic potential and the maximum rate of rise of depolarization

In the preceding section, voltage dependency of the maximum rate of rise of depolarization has been demonstrated in S-A node cells. Since the maximum rate of rise of depolarization is extremely low compared with those in other myocardial fibers, the validity of the sigmoidal relationship was tested by solving the empirical equation of HodGKIN and HuxLeY (1952) with respect to the slope factor $s$ :

$$
h=\frac{1}{1+\exp \frac{V h-V}{s}}
$$

where $h$ is the fraction of the highest value observed for the maximum rate of rise of depolarization. $\quad V$ is the holding potential in $\mathrm{mV}$, and $V h$ the potential at which $h$ is half maximum. The solution of equation (1) is

$$
s=\frac{0.434(V h-V)}{\log \frac{1-h}{h}} .
$$

Therefore, the sigmoidal relationship between the membrane potential and the 
maximum rate of rise of depolarization can be tested by examining the constancy of $s$.

Application of constant current to the S-A node cell was made by the same method as in the previous section (Fig. 6). The results were qualitatively similar to those of Fig. 5. The series of experimental data in the same cell are plotted in Fig. 7A, where the open circles were obtained from the action potential during the application of depolarizing current. The solid circles indicate that the data

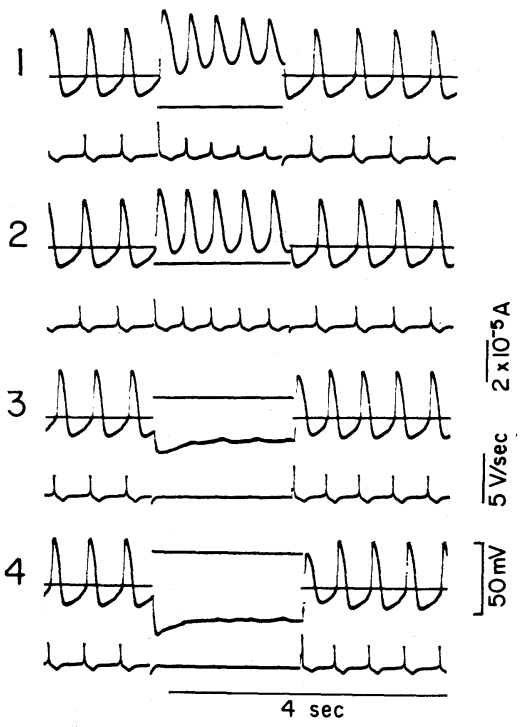

Fig. 6. Effects of change of membrane potential on action potential. Traces 1-4 represent recordings of current (top), action potentials (middle), and the maximum rate of rise of depolarization (bottom). 1 and 2: effects of depolarizing current. 3 and 4: effects of hyperpolarizing current.

were obtained from the initial highest membrane potential during application of hyperpolarizing current, while the open triangles show that the membrane potentials were measured immediately before the cessation of hyperpolarizing current. In Fig. 7B, the membrane potential are plotted against $\log (1-h) / h$. The straight line drawn by the least squares method from the data obtained during the depolarizing current (open circles) passed through four points where the data were obtained from the highest membrane potential during hyperpolarization (solid circles). Experimental data are in good agreement with the smooth sigmoidal curve drawn from equation (1) with $V h=39 \mathrm{mV}$ and $s=10.6$ in Fig. 7A.

Sigmoidal relationship measured by the combination of the current clamp and voltage clamp

To ensure constant membrane potential during the current application, the "voltage clamp" method was applied (Fig. 8). The maximum rate of rise of de- 

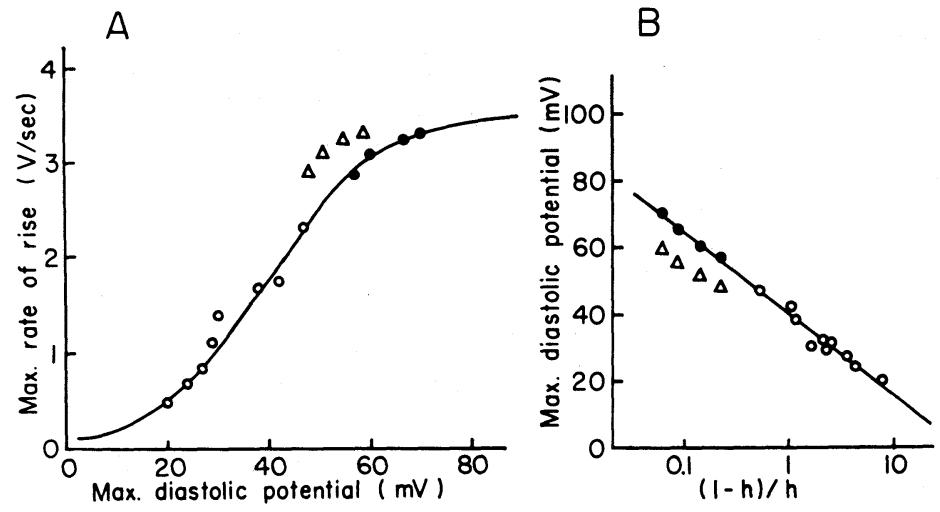

Fig. 7. Sigmoidal relationship between the maximum diastolic potential and the maximum rate of rise of depolarization. Open circles were obtained from the action potential during the application of the depolarizing current. During the application of hyperpolarizing current, the initial highest membrane potential (solid circles) and the potential immediately before the disruption of the current (triangles) were measured. A straight line was drawn by the least squares method from the open circles in B. Smooth sigmoidal curve was drawn from equation (1) with $V h=39.0 \mathrm{mV}$ and $s=10.6$, which were determined in $\mathrm{B}$.
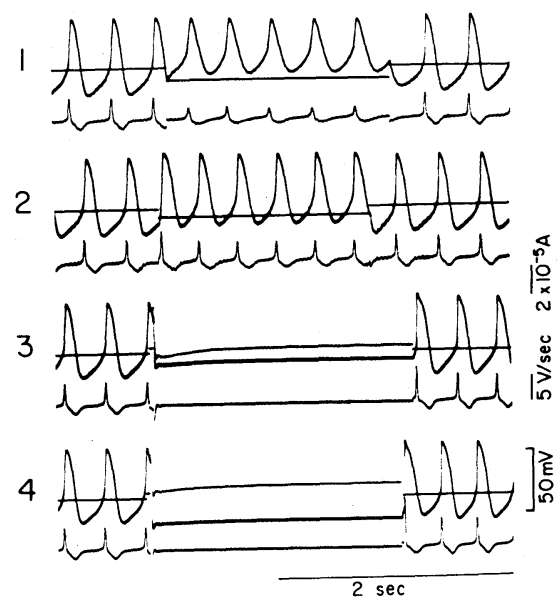

Fig. 8. Effects of holding the membrane potential at a constant level on the maximum rate of rise of depolarization of the action potential. Three tracings in each row represent current (top), action potentials (middle), and the maximum rate of rise of depolarization (bottom). In 3 and 4, the membrane was clamped and the maximum rate of rise of depolarization was measured from the action potential at the release of the clamp. 
polarization immediately after the membrane was released from the "voltage clamp" was greater than that of the control. The solid circles in Fig. 9A indicate that the data were obtained by the "voltage clamp" method. The open circles in Fig. 9A indicate that the data were obtained during the application of depolarizing current. The relationship between $(1-h) / h$ and the membrane potential was plotted according to the procedure shown in Fig. 7. Two straight lines determined by the least squares method show $s=13.5$ for the solid circles and $s=$ 13.2 for the open circles, demonstrating a parallel relationship between these two lines. The smooth curve drawn using equation (1) with $V h=45 \mathrm{mV}$ and $s=13.5$ for the solid circle, and with $V h=65 \mathrm{mV}$ and $s=13.2$ for the open circle fitted well with the experimental data (Fig. 9A). Thus a sigmoidal relationship between the membrane potential and the maximum rate of rise of depolarization was also demonstrated. The maximum value of the maximum rate of rise of depolarization ranged from 2.1 to $10.0 \mathrm{~V} / \mathrm{sec}$ in pacemaking cells in 16 examples.

A

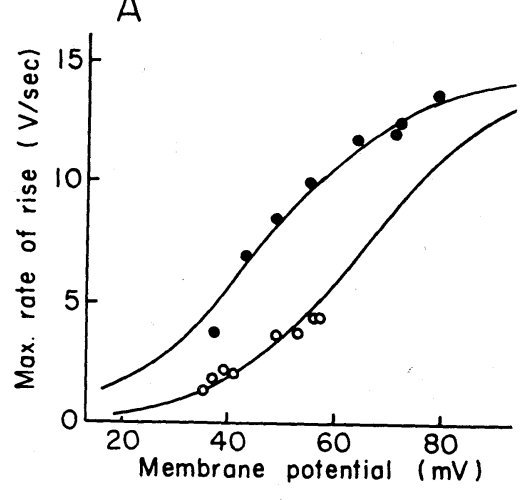

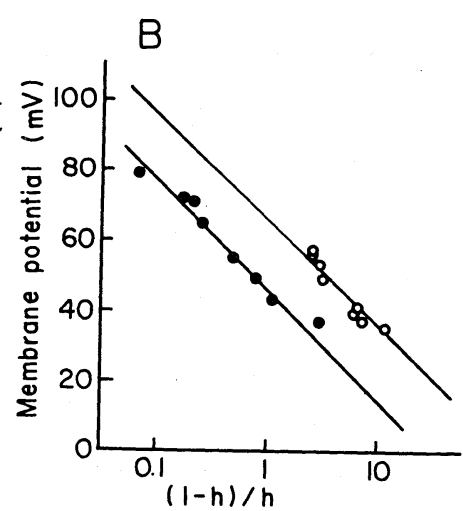

Fig. 9. Sigmoidal relationship between the membrane potential and the maximum rate of rise of depolarization. Open circles were obtained during the application of depolarizing current. The maximum rate of rise of depolarization measured from the action potential immediately after the "voltage clamp" was plotted against the holding potential (solid circles). In A, a smooth sigmoidal curve was drawn from equation (1). In B, the straight lines were determined by the least squares method.

\section{Effects of temperature on the sigmoidal curve of the $S$-A node cells}

In Fig. 10, the effect of temperature on the action potentials of the S-A node cell at various membrane potentials is shown. In A, experiments were performed at $36^{\circ} \mathrm{C}$, while in $\mathrm{B}$, the data were obtained at $26^{\circ} \mathrm{C}$. At $26^{\circ} \mathrm{C}$, the frequency of spontaneous activity and the maximum rate of rise of depolarization were reduced. The membrane was depolarized by $4 \mathrm{mV}$ at $26^{\circ} \mathrm{C}$. This slight depolarization at low temperature is in accord with the previous findings (YAMAGISHI and SANO, 1967). The sigmoidal characteristics of these results were examined by the same procedure as in the previous section (Fig. 11). 


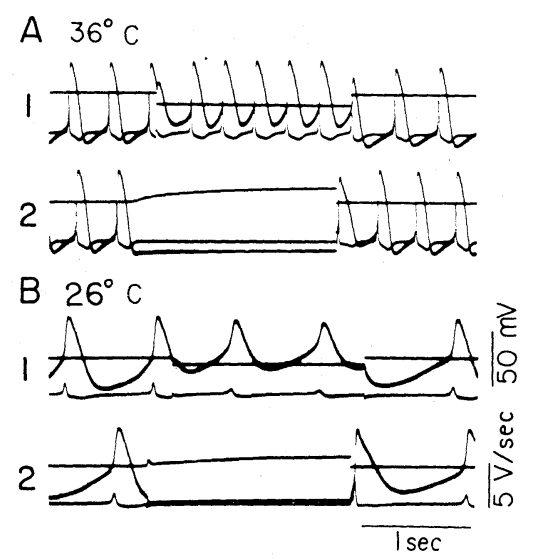

Fig. 10. Effects of temperature on the action potentials at various membrane potentials. A: in $36^{\circ} \mathrm{C}$ Tyrode solution. B: in $26^{\circ} \mathrm{C}$ Tyrode solution. Tracings are as defined in Fig. 8. 1: effects of depolarizing current. 2: effects of holding the membrane potential at high levels.
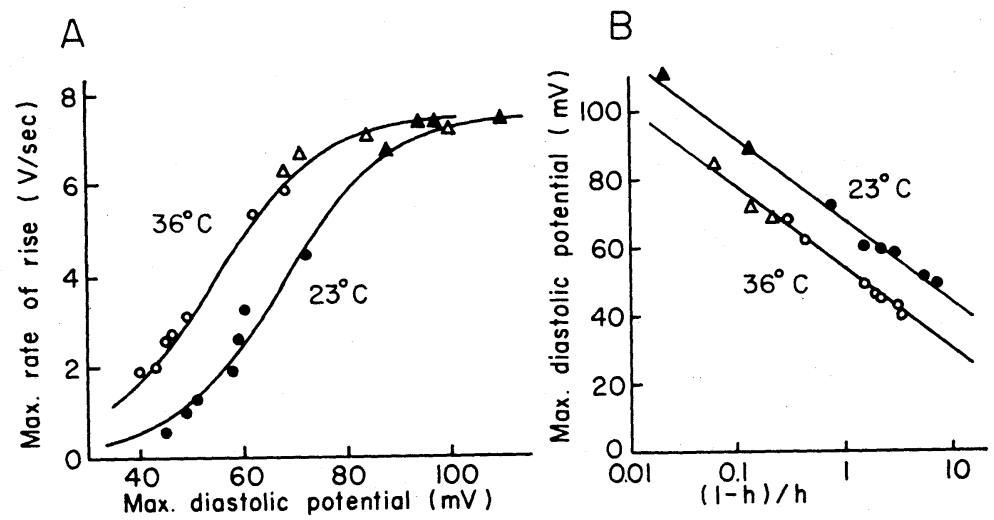

Fig. 11. Sigmoidal relationship between the maximum diastolic potential and the maximum rate of rise of depolarization in two different temperatures. Circles were obtained from the action potential during the application of depolarizing current. During the application of hyperpolarizing current, the highest initial membrane potential (triangles) was plotted. Two sigmoidal curves in A and lines in B were drawn in the same way as in Fig. 7. Open symbols indicate that the data were obtained at $36^{\circ} \mathrm{C}$, while solid symbols were obtained at $23^{\circ} \mathrm{C}$.

Experimental results made a good fit to the sigmoidal curve drawn from equation (1) with a value of $67 \mathrm{mV}$ for $V h$ and 10.4 for $s$ for the lower temperature. The sigmoidal curve at $36^{\circ} \mathrm{C}$ is $53 \mathrm{mV}$ for $V h$ and 10.4 for $s$. Four examples of the effects of lower temperature on the S-A node are given in Table 2. All examples show a similar trend. Similarity of the values of the slope factors for two 
Table 2. Summary of the maximum value of the maximum rate of rise of depolarization $\left(V_{\max }\right)$, membrane potential at which $h=1 / 2(V h)$, and slope factor $(s)$ measured from different cells.

\begin{tabular}{|c|c|c|c|c|c|}
\hline \multicolumn{2}{|r|}{ Cells } & \multirow{2}{*}{$\begin{array}{c}\dot{V}_{\max } \\
5.8\end{array}$} & \multirow{2}{*}{\begin{tabular}{|l|}
$V h$ \\
39
\end{tabular}} & \multirow{2}{*}{$\frac{s}{11.5}$} & \multirow{2}{*}{$\begin{array}{l}\mathbf{T}^{\circ} \mathrm{C} \\
36\end{array}$} \\
\hline 1 & pacemaking cell & & & & \\
\hline 2 & $"$ & 3.8 & 39 & 10.6 & 36 \\
\hline 3 & $"$ & 7.6 & 53 & 10.4 & 36 \\
\hline 4 & $"$ & 10.0 & 67 & 18.2 & 36 \\
\hline 5 & $"$ & 14.5 & 65 & 13.2 & 36 \\
\hline 6 & $"$ & 7.0 & 53 & 8.7 & 36 \\
\hline 7 & $"$ & 12.0 & 66 & 17.6 & 36 \\
\hline \multicolumn{2}{|c|}{ Average $(n=7)$} & 8.7 & 55 & 12.9 & (36) \\
\hline 1 & pacemaking cell & $5.8^{*}$ & 60 & 9.1 & 28 \\
\hline 2 & $"$ & $3.8^{*}$ & 48 & 10.0 & 27 \\
\hline 3 & $"$ & $7.6^{*}$ & 67 & 10.4 & 23 \\
\hline 4 & $"$ & $10.0^{*}$ & 72 & 16.9 & 26 \\
\hline \multicolumn{2}{|c|}{ Average $(n=4)$} & 6.8 & 62 & 11.6 & $(23-28)$ \\
\hline 8 & follower cell & 28.0 & 55 & 16.5 & 36 \\
\hline 9 & $"$ & 12.4 & 42 & 14.0 & 36 \\
\hline 10 & $"$ & 12.5 & 61 & 15.6 & 36 \\
\hline \multicolumn{2}{|c|}{ Average $(n=3)$} & 17.6 & 53 & 15.4 & (36) \\
\hline
\end{tabular}

* $V_{\max }$ in the lower temperature was assumed to be similar to that in the normal temperature.

different temperatures suggests that the sigmoidal relation was shifted toward the negative direction by lower temperature.

\section{DISCUSSION}

When the S-A node tissue was dissected into several small pieces in this experiment, some dissected pieces continued spontaneous activity, while others became quiescent. In these quiescent pieces of tissue, spontaneous activity developed within a few hours after dissection. In each spontaneously active piece of tissue, two types of action potentials were observed: one showed a smooth transition and the other showed an abrupt transition from the prepotential to the upstroke of the action potential. However, the shape of the action potential was changeable and only the action potential showing the smooth transition was observed in further dissected smaller pieces of the S-A node tissue.

These findings are in good agreement with the concept that cells capable of self-excitation are scattered throughout the region surrounded by the sinoatrial ring bundle in rabbits (PAES DE CARVAlHo et al., 1959; BROOKS and LU, 1972). Therefore, an S-A node cell capable of self-excitation shows three different functional states: the pacemaking state in which the action potential is self-initiated, the following state in which the action potential is triggered by other pacemaking cells, and the quiescent state. 
The electrical characteristics of the pacemaking cell in the present experiment was in good agreement with those of the true pacemaker cell observed by other authors (West, 1955; Hoffman and Cranefield, 1960; Sano and Yamagishi, 1965; TodA and West 1967; TODA, 1968; LU, 1970). Thus, the activity of the pacemaking cell in this experiment might represent the physiological characteristics of the true pacemaker cell of the S-A node. The maximum diastolic potential and the amplitude of the action potential of the follower cells were similar to those of pacemaking cells. However, the maximum rate of rise of depolarization in the pacemaking cell was lower than in the follower cell, as described by SANO and YAMAGishi (1965). This defference was partly due to the inactivation processes during the slow diastolic depolarization and partly due to the sampling sites. The follower type of action potential was frequently recorded near the crista terminalis and sinoatrial ring bundle (PAES DE CARVAlHo et al., 1959). The mechanism underlying the differences in the functional states of the S-A node cell is unclear.

The fact that the maximum rate of rise of depolarization of the S-A node cell was reduced in proportion to the reduction of $\left[\mathrm{Na}^{+}\right]_{0}$ (Figs. 4 and 5) indicates that $\mathrm{Na}^{+}$plays an essential role in producing the initial phase of the action potential as in other myocardial fibers. However, the amplitude of action potential was not reduced by lowering $\left[\mathrm{Na}^{+}\right]_{\circ}$ as markedly as expected from the Nernst equation. This fact suggests that the ionic current entering the S-A node cell at the time of the peak of the action potential is carried by other ions, such as $\mathrm{Ca}^{++}$ (NIEDERGERKE and ORKAND, 1966). The existence of a fast $\mathrm{Na}^{+}$current underlying the initial rapid phase of the myocardial action potential was demonstrated in the Purkinje fiber (Dudel et al., 1966), frog atrial tissue (RougIER et al., 1968; HAAs et al., 1971; SeYAMA, 1971), and ventricular fibers (BEeler and Reuter, 1970a), and an S-shaped relation between the steady state inactivation and membrane potential was also demonstrated in these myocardial fibers. However, within a specialized conduction system of the myocardium, such as S-A node and A-V node cells, a group of cells was observed whose rapid phase of the action potential was apparently very slow.

In a pacemaking cell of the S-A node of rabbits, the maximum rate of rise of depolarization of the action potential, which is a good indicator of the fast inward current in other myocardiums, ranged only from 2 to $6 \mathrm{~V} / \mathrm{sec}$. A definite sigmoidal relationship between the maximum rate of rise of depolarization and membrane potential was confirmed in the S-A node cells in this study. It is suggested that there are also inactivation mechanisms in the S-A node cell as in the A-V node fiber (SHIGETo and IrISAWA, 1972).

DUDEL and RÜDEL (1970) studied the effect of low temperature on the fast $\mathrm{Na}^{+}$current in Purkinje fibers. They found that the sigmoidal relationship between $\mathrm{Na}^{+}$current and membrane potential was shifted by about $15 \mathrm{mV} / 10^{\circ} \mathrm{C}$ toward a more negative potential. A similar effect of temperature on the sigmoidal 
relationship was observed in the S-A node cell in this experiment. The sigmoidal relationship found in the S-A node cell largely differs from that in the Purkinje fiber on two points. The slope factor of 12.9 in the S-A node cell was larger than that of 5 in the Purkinje fiber (Weidmann, 1955). Thus, the sodium system of the Purkinje fiber was found to be inactivated at about $-60 \mathrm{mV}$ and to be fully activated at $-90 \mathrm{mV}$. In the $\mathrm{S}-\mathrm{A}$ node cell, the system was fully activated at $-90 \mathrm{mV}$, but was not fully inactivated even at membrane potential as low as $-40 \mathrm{mV}$. It can be stated that the $\mathrm{S}-\mathrm{A}$ node cell is resistive to inactivation. The other difference is the extremely small magnitude of the maximum value of the maximum rate of rise of depolarization in the S-A node cell.

This work was supported by a research grant from the Japanese Ministry of Education and the Japan Heart Foundation.

\section{REFERENCES}

Beeler, G. W. and Reuter, H. (1970a) Voltage clamp experiments on ventricular myocardial fibres. J. Physiol., 207: 165-190.

BeEler, G. W. and Reuter, H. (1970b) Membrane calcium current in ventricular myocardial fibres. J. Physiol., 207: 191-209.

Brooks, C. MCC. and LU, H. H. (1972) The sinoatrial pacemaker of the heart. Charles C. Thomas Publ., Springfield, Ill.

Dudel, J., Peper, K., Rüdel, R., and trautwein, W. (1966) Excitatory membrane current in heart muscle (Purkinje fibers). Pflügers Arch., 292: 255-273.

Dudel, J. and RüDEL, R. (1970) Voltage and time dependence of excitatory sodium current in cooled sheep Purkinje fibres. Pflügers Arch., 315: 136-158.

GiebisCH, G. and WeIDMANN, S. (1971) Membrane currents in mammalian ventricular heart muscle fibers using a voltage-clamp technique. J. Gen. Physiol., 57: 290-296.

HAAS, H. G., KeRN, R., EINWÄCHTER, H. M., and TARR, M. (1971) Kinetics of Na inactivation in frog atria. Pflügers Arch., 323: 141-157.

Hoffman, B. F. and Cranefield, P. F. (1960) Electrophysiology of the heart. McGraw-Hill, New York.

Hodgkin, A. L. and Huxley, A. F. (1952) The dual effect of membrane potential on sodium conductance in the giant axon of Loligo. J. Physiol., 116: 497-506.

IRISAWA, H. (1972) Electrical activity of rabbit sino-atrial node as studied by a double sucrose gap method. In Proceedings of the Satellite Symposium of the XXVth International Congress of Physiological Sciences. ed, by Rijlant, P. Presses Academiques Europeennes, Bruxelles.

Lenfant, J., Mironneau, J., Gargouil, Y-M., and Galand, G. (1968) Analyse de l'activité électrique spontanée du centre de l'automatisme cardiaque de lapin par inhibiteurs de perméabilités membranaires. C. R. Acad. Sci. (Paris), 266: D-901-904.

LU, H. H. (1970) Shifts in pacemaker dominance within the sinoatrial region of cat and rabbit hearts resulting from increase of extracellular potassium. Circ. Res., 26: 339-346.

Morad, M. and Trautwein, W. (1968) The effect of the duration of the action potential on contraction in the mammalian heart muscle. Pfügers Arch., 299: 66-82.

Niedergerke, R. and Orkand, R. K. (1966) The dependence of the action potential of the frog's heart on the external and intracellular sodium concentration. J. Physiol., 184: 312-334.

Paes de Carvalho, A., De Mello, W. C., and Hoffman, B. F. (1959) Electrophysiological 
evidence for specialized fiber types in rabbit atrium. Am. J. Physiol., 196: 483-488.

RoUgier, O., VASSORT, G., and STÄMPfLI, R. (1968) Voltage clamp experiments on frog atrial heart muscle fibres with the sucrose gap technique. Pflügers Arch., 301: 91-108.

SAno, T. and Yamagishi, S. (1965) Spread of excitation from the sinus node. Circ. Res., 16: 423-430.

SEYAMA, I. (1969) Effect of high calcium concentration on the action potential of the skate heart. Am. J. Physiol., 216: 687-692.

SEyamA, I. (1971) Characteristics of transient current in the atrium myocardium of the frog. J. Physiol. Soc. Jap., 33: 729-730.

Shigeto, N. and Irisawa, H. (1972) Slow conduction in the atrioventricular node of the cat: A possible explanation. Experimentia, 28: 1442-1443.

ToDA, N. (1968) Influence of sodium ions on the membrane potential of the sino-atrial node in response to sympathetic nerve stimulation. J. Physiol., 196: 677-691.

TodA, N. and West, T. C. (1967) Interactions of $\mathrm{K}, \mathrm{Na}$, and vagal stimulation in the S-A node of the rabbit. Am. J. Physiol., 212: 416-423.

WEST, T. C. (1955) Ultramicroelectrode recording from the cardiac pacemaker. J. Pharmacol. Exp. Ther., 115: 283-290.

WEST, T. C. (1961) Effects of chronotropic influences on subthreshold oscillations in the sinoatrial node. In The Specialized Tissues of the Heart, ed. by Paes DE Carvalho, A., DE Mello, W. C., and Hoffman, B. F. Elsevier, New York, pp. 81-94.

WeIDMANN, S. (1955) The effect of the cardiac membrane potential on the rapid availability of the sodium-carrying system. J. Physiol., 127: 213-224.

Woodbury, J. W. and Brady, A. J. (1956) Intracellular recording from moving tissues with a flexbly mounted ultramicroelectrode. Science, 123: 100.

YAMAGISHI, S. and SANO, T. (1966) Effect of tetrodotoxin on the pacemaker action potential of the sinus node. Proc. Japan Acad., 42: 1194-1196.

YAMAGISHI, S. and SANO, T. (1967) Effect of temperature on pacemaker activity of rabbit sinus node. Am. J. Physiol., 212: 829-834. 